\title{
Preparation and Characterization of Ag@Ti02/a- Fe203 Ternary Nanocomposite for enhanced visible light photocatalytic performance
}

Nesrine Ben Saber

Taif University

Amine Mezni ( $\square$ aminemezni@yahoo.fr )

Taif University https://orcid.org/0000-0002-2915-4834

\section{Research Article}

Keywords: solvothermal, hydrothermal, silver, titanium dioxide, iron oxide, photocatalyst

Posted Date: August 19th, 2021

DOl: https://doi.org/10.21203/rs.3.rs-814762/v1

License: (c) (1) This work is licensed under a Creative Commons Attribution 4.0 International License.

Read Full License 


\section{Abstract}

In this work, ternary $\mathrm{Ag} @ \mathrm{TiO}_{2} / \mathrm{a}-\mathrm{Fe}_{2} \mathrm{O}_{3}$ nanocomposite were synthesized via solvothermal chemical reduction method using $\mathrm{N}, \mathrm{N}$-dimethylformamide (DMF) as solvent and reducing agent. The chemical procedure involves the use of only metals precursors without the need to use any other surfactants or capping agents. Physicochemical properties of the designed photocatalyst are found by means of various modern techniques. XRD data confirmed the high crystallinity of the obtained ternary nanocomposite. On the other hand, using TEM and HRTEM instruments, the shape and morphology of the $\mathrm{Ag} @ \mathrm{TiO}_{2} / \mathrm{a}-\mathrm{Fe}_{2} \mathrm{O}_{3}$ nanocomposite were found to be spherical with an average particle size of $150 \mathrm{~nm}$. The UV-Vis measurement shows that $\mathrm{Ag} @ \mathrm{TiO}_{2} / \mathrm{a}-\mathrm{Fe}_{2} \mathrm{O}_{3}$ as photocatalyst exhibited good photo response in the visible region. The effect of preparation method and the performance of the designed photocatalyst were evaluated by photodegradation measurements of MB under visible light irradiation. We observed that the combination of metallic silver nanoparticles (AgNPs) and hematite iron oxide ( $\mathrm{a}$ $\left.\mathrm{Fe}_{2} \mathrm{O}_{3}\right)$ with titanium dioxide $\left(\mathrm{TiO}_{2}\right)$ enhance the photocatalytic activity of the ternary $\mathrm{Ag} @ \mathrm{TiO}_{2} / \mathrm{a}-\mathrm{Fe}_{2} \mathrm{O}_{3}$ photocatalyst compared to bare $\mathrm{TiO}_{2}$ suggesting its potential for many purification applications.

\section{Introduction}

Environmental pollution resulting from numerous artificial and industrial events is essentially constituted of inorganic, organic and harmful pollutants such as antibiotic, pesticides and dyes [1]. Generally, the most adopted methods to decompose pollutions such as chemical, heating, or biological process are found to be very expensive and ineffective mostly for the degradation of antibiotic. In recent years, nanomaterials are found to be very useful for different applications [2-4]. On the other side, photocatalytic reactions have been widely suggested as green solution to decompose many categories of pollutants under mild conditions and under solar light source [5-11]. However, the photodegradation mechanism involves the presence of only a photocatalyst and a light as exciting source. This process can mineralize pollutants to harmless products such as carbon dioxide and water and therefore produces useful products. Among the semiconductor photocatalyst, titanium dioxide $\left(\mathrm{TiO}_{2}\right)$ can be considered as the most promising photocatalyst in recent years due to its high stability and easy to prepare in different shape and size [12-20]. On the other hand, unfortunately, $\mathrm{TiO}_{2}$ nanoparticles suffer from its large energy gap (3.2 eV), which limits its usage under visible light source [14]. The second inconvenient which inhibits the photocatalytic efficiency of $\mathrm{TiO}_{2}$ is related to the high charge carrier recombination rate during the photodegradation reaction [15]. To resolve this problem, the synthesis of hybrid nanocomposite was found to be very efficient for decreasing the energy gap and the separation of charge carrier recombination. Using a simple two-step hydrothermal and photo-reduction method, Zhang et al. prepared ternary $\mathrm{BiVO}_{4} / \mathrm{NiS} / \mathrm{Au}$ nanocomposites with efficient charge separations for enhanced visible light photocatalytic performance [11]. They found that the photodegradation activity was enhanced 4.25 times compared to pure $\mathrm{BiVO}_{4}$. Using the sol-gel method, Khasawnhem et al. [1] designed hybrid $\mathrm{Fe}_{2} \mathrm{O}_{3}-\mathrm{TiO}_{2}$ heterogenous photocatalyst for the removal of acetaminophen (ACT) pharmaceutical compound. The obtained results revealed that photodegradation rate of ACT was observed at $\mathrm{pH}=11$ and the 
photocatalytic activity was further optimized compared to bare $\mathrm{TiO}_{2}$. Sahu et al. developed for the first time a combined sol-gel-assisted hydrothermal method to prepare Copper/ $/ \mathrm{TiO}_{2} /$ graphene oxide ternary nanocomposites (CUTGR) [2]. This photocatalyst exhibited high photocatalytic activity. Indeed, preliminary results show that an optimal loading of $\mathrm{Cu}$ and graphene in $\mathrm{TiO}_{2}$ matrix can significantly enhance the surface and optical response of the designed nanocomposites and thereby allowing it to be an efficient ternary photocatalyst for many applications.

In this context, the main purpose of this work is to prepare a ternary system based on titanium dioxide $\left(\mathrm{TiO}_{2}\right)$ nanoparticles with excellent light absorption and high photocatalytic efficiency. In recent years, iron oxide more precisely the hematite phase $\left(\mathrm{a}-\mathrm{Fe}_{2} \mathrm{O}_{3}\right)$ was found to be an ideal metal oxide to expand the photo response of $\mathrm{TiO}_{2}$ and therefore enhance its photocatalytic performance [16-19]. On the other side, silver nanoparticles (AgNPs) are a plasmonic metal nanoparticles with their intrinsic plasmonic properties can increase the electrons activity over the surface of $\mathrm{TiO}_{2} \mathrm{NPs}$ and slows down the recombination of $\mathrm{e} / \mathrm{h}+$ pairs. Consequently, the loading of both hematite iron oxide $\left(\mathrm{a}-\mathrm{Fe}_{2} \mathrm{O}_{3}\right)$ and silver nanoparticles (AgNPs) at the $\mathrm{TiO}_{2}$ surface can subsequently boost the photocatalytic activity of the final nanocomposite. The present paper develop a simple one pot solvothermal protocol to synthesize ternary $\mathrm{Ag} @ \mathrm{TiO}_{2} / \mathrm{a}-\mathrm{Fe}_{2} \mathrm{O}_{3}$ nanocomposite using $\mathrm{N}, \mathrm{N}$-dimethylformamide (DMF) as solvent and reducing agent without recourse to use any capping agent or surfactant. The photodegradation reaction against MB dyes prove the efficiency of this ternary system compared to bare $\mathrm{TiO}_{2}$ or a-Fe $\mathrm{O}_{3} \mathrm{NPs}$.

\section{Materials And Methods}

\subsection{Measurement and Characterizations}

Powder X-ray diffraction (D8 Advance Bruker, USA) technique was performed to study the obtained crystalline phase. Shape and size of the photocatalyst was examined using transmission electron microscope (Philips Tecnai F-20 SACTEM working at 200 kV). X-ray photoelectron spectrometry (XPS, Kratos Axis Ultra DLD) was recorded for further elemental analysis. Optical response was investigated via UV-Visible Perkin-Elmer Lambda 11 spectrophotometer. To study the charge recombination process, Photoluminescence (PL) measurements were adopted using Jobin Yvon Flurolog-3-11 instrument equipped with $450 \mathrm{~W}$ xenon lamp. Photocatalytic test were evaluated at room temperature for removal of MB molecules dyes under visible light illumination (lamp of $400 \mathrm{~W}$ Metal Halide. The solution $\mathrm{pH}$ was fixed at 7. The photocatalyst amoun was fixed to $7 \mathrm{mg}$ during the photocatalytic test. The initial MB concentration solution was $3.0 .10^{-5} \mathrm{~mol} / \mathrm{L}$.

\subsection{Synthesis of $\mathrm{Ag} @ \mathrm{TiO}_{2} / \mathrm{a}-\mathrm{Fe}_{2} \mathrm{O}_{3}$ Photocatalyst}

Iron oxide was first synthesized using the hydrothermal process [21] by mixing iron chloride and ammonium dihydrogen phosphate. After that, the mixture was transferred into a Teflon-lined autoclave and heated at $220^{\circ} \mathrm{C}$ for $48 \mathrm{~h}$. $\mathrm{Ag} @ \mathrm{TiO}_{2} / \mathrm{a}-\mathrm{Fe}_{2} \mathrm{O}_{3}$ photocatalyst was prepared as follows: Titanium(IV) 
butoxide $(5 \mathrm{ml})$ and silver nitrate $(100 \mathrm{mg})$ were first dissolved in $50 \mathrm{ml}$ of $\mathrm{N}, \mathrm{N}$-dimethylformamide (DMF) at room temperature. The resulting mixture was magnetically stirred, and an adequate amount of asprepared iron oxide nanoparticles $(10 \mathrm{mg})$ was added. Then the obtained final mixture was heated at 153 ${ }^{\circ} \mathrm{C}$ for $2 \mathrm{~h}$. The recuperated powder was then calcinated in air at $400^{\circ} \mathrm{C}$ for $2 \mathrm{~h}$ to produce the desired ternary $\mathrm{Ag} @ \mathrm{TiO}_{2} / \mathrm{a}-\mathrm{Fe}_{2} \mathrm{O}_{3}$ nanocomposite.

\section{Results And Discussion}

Powder X-ray diffraction patterns of $\mathrm{TiO}_{2}, \mathrm{a}-\mathrm{Fe}_{2} \mathrm{O}_{3}$ and ternary $\mathrm{Ag} @ \mathrm{TiO}_{2} / \mathrm{a}-\mathrm{Fe}_{2} \mathrm{O}_{3}$ photocatalyst are shown in Fig. 1. As can be observed, in the diffractogram of the ternary nanocomposite, all diffractions peaks characteristic of titanium dioxide, silver and iron oxide are detected. No other peaks or impurities can be detected which prove the purity of the obtained sample. Based on the XRD data, we can assume the successful fabrication of the ternary $\mathrm{Ag} @ \mathrm{TiO}_{2} / \mathrm{a}-\mathrm{Fe}_{2} \mathrm{O}_{3}$ heterojunction. Figure 2 displays the morphology of the ternary photocatalyst. As shown, we can detect the deposition of both AgNPs and a$\mathrm{Fe}_{2} \mathrm{O}_{3} \mathrm{NPs}$ on the $\mathrm{TiO}_{2}$ surface. Furthermore, the HRTEM image confirms the ternary heterojunction by the presence of (111), (003) and (101) lattice spacing characteristic of $\mathrm{Ag}, \mathrm{a}-\mathrm{Fe}_{2} \mathrm{O}_{3}$ and $\mathrm{TiO}_{2} \mathrm{NPs}$, respectively. The SAED pattern further confirms the presence of the three system by the detection of all characteristic electron diffraction responses. To further confirm the successful synthesis of $\mathrm{Ag} @ \mathrm{TiO}_{2} / \mathrm{a}-$ $\mathrm{Fe}_{2} \mathrm{O}_{3}$ nanocomposites, XPS mesearement was performed to study the chemical composition and their corresponding valence states (Fig. 3). The XPS spectra of the asprepared sample are shown in Fig. 3. In the Ti $2 p$ spectrum, two peaks at $458 \mathrm{eV}$, and $465 \mathrm{eV}$ were assigned to Ti $2 \mathrm{p} 3 / 2$ et Ti $2 \mathrm{p} 1 / 2$, respectively. Values agree well with the $\mathrm{Ti}^{4+}$ state in $\mathrm{TiO}_{2}$. The spectrum of Fe which exhibites also two peaks at 711 $\mathrm{eV}$ and $725 \mathrm{eV}$ can be ascribed to the $\mathrm{Fe} 2 \mathrm{p}$ element of hematite $\mathrm{a}-\mathrm{Fe}_{2} \mathrm{O}_{3}$. In the case of $\mathrm{O} 1 \mathrm{~s}$, it can be detected the presence of asymmetrical peak located at $529.9 \mathrm{eV}$ which can be attributed to lattice oxygen and surface oxygen. For Ag element, two characteristic peaks are located at 273.6 and $367.8 \mathrm{eV}$ which can be assigned to $\mathrm{Ag} 3 \mathrm{~d} 3 / 2$ et $\mathrm{Ag} 3 \mathrm{~d} 5 / 2$ respectively. Values agree well with $\mathrm{Ag}^{0}$ metal. The deconvolution of the XPS peaks of Ag (Figure S1) revealed the presence of peaks characteristic of Ag-O bonds. As mentioned above, HRTEM results showed the deposotion of AgNPs on both $\mathrm{TiO}_{2}$ and $\mathrm{a}-\mathrm{Fe}_{2} \mathrm{O}_{3}$ surfaces. The XPS data agree well with the HRTEM observation. However, the presence of XPS peaks characteristic of $\mathrm{Ag}-\mathrm{O}$ bonds confirmed the the adsorption processes of $\mathrm{AgNPs}$ on $\mathrm{TiO}_{2}$ and $\mathrm{a}-\mathrm{Fe}_{2} \mathrm{O}_{3}$ surfaces, through chemical oxygen bonds. This chemisorption between AgNPs and metals oxide ensures the formation of .he ternary heterojunction and avoiding metal desorption [12,13]. The optical properties of $\mathrm{Ag} @ \mathrm{TiO}_{2} / \mathrm{a}-\mathrm{Fe}_{2} \mathrm{O}_{3}$ nanocomposite, hybrid $\mathrm{Ag} @ \mathrm{TiO}_{2}$ and as well as bare $\mathrm{TiO}_{2}$ and $\mathrm{a}-\mathrm{Fe}_{2} \mathrm{O}_{3}$ were

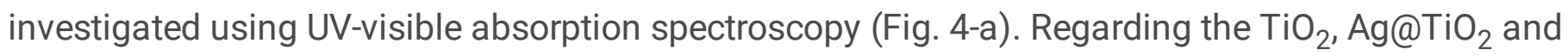
$\mathrm{Ag} @ \mathrm{TiO}_{2} / \mathrm{a}-\mathrm{Fe}_{2} \mathrm{O}_{3}$ spectra, each spectrum shows an absorption edge at $346 \mathrm{~nm}$ that corresponds to a band gab energy of $3.85 \mathrm{eV}$. Result agree well agreement with the band gap energy reported in the literature. On the other hand, for $\mathrm{Ag} @ \mathrm{TiO}_{2}$ and $\mathrm{Ag} @ \mathrm{TiO}_{2} / \mathrm{a}-\mathrm{Fe}_{2} \mathrm{O}_{3}$, an additional absorption band located between 435 and $480 \mathrm{~nm}$ which can be attributed to the surface plasmon resonance of silver nanoparticles. On the other side, iron oxide is generally reported to absorb strongly in the ultraviolet (UV) 
region. However, regarding the $\mathrm{a}-\mathrm{Fe}_{2} \mathrm{O}_{3}$ and $\mathrm{Ag} @ \mathrm{TiO}_{2} / \mathrm{a}-\mathrm{Fe}_{2} \mathrm{O}_{3}$ spectra, effectively an absorption edge located at $245 \mathrm{~nm}$ can clearly detected and can be assigned to the electronic transition in the hematite $\alpha$ $\mathrm{Fe}_{2} \mathrm{O}_{3}$ structure. The change of the absorption behaviour of $\mathrm{Ag} @ \mathrm{TiO}_{2} / \mathrm{a}-\mathrm{Fe}_{2} \mathrm{O}_{3}$ compared to bare $\mathrm{TiO}_{2}$ and $\mathrm{a}-\mathrm{Fe}_{2} \mathrm{O}_{3}$, implies that the charge-transfer transition between the three materials occurs while loading Ag to $\mathrm{TiO}_{2}$ and $\mathrm{a}-\mathrm{Fe}_{2} \mathrm{O}_{3}$. This observation was further supported by PL measurements (Fig. 4-b). Indeed, as can be seen, the PL spectrum of all samples exhibited blue emission located at $445 \mathrm{~nm}$. It has been reported that the visible luminescence, related to deep level emissions, mainly results from defects such as interstitials and oxygen vacancies. On the other hand, as can be seen in Fig. 4-b, a considerable PL emission quenching of $\mathrm{Ag} @ \mathrm{TiO}_{2} / \mathrm{a}-\mathrm{Fe}_{2} \mathrm{O}_{3}$ nanocomposite was observed which indicated that a lower recombination rate of the photogenerated carrier could be efficiently achieved resulting from the synergistic effects between $\mathrm{Ag}, \mathrm{TiO}_{2}$ and $\mathrm{a}-\mathrm{Fe}_{2} \mathrm{O}_{3}$. This result implying that the intimate contact between $\mathrm{Ag}, \mathrm{TiO}_{2}$ and $\mathrm{a}-\mathrm{Fe}_{2} \mathrm{O}_{3}$ could make for the vectorial migrate of charge carriers among the nanocomposite, enhancing the photogenerated carrier's separation and therefore improving the photocatalytic efficiency.

The photocatalytic efficiencies of $\mathrm{Ag} @ \mathrm{TiO}_{2} / \mathrm{a}-\mathrm{Fe}_{2} \mathrm{O}_{3}$ nanocomposites were evaluated using $\mathrm{MB}$ dyes as a model pollutant. Photocatalytic activities of hybrid $\mathrm{Ag} @ \mathrm{TiO}_{2}$, bare $\mathrm{TiO}_{2}$ and $\mathrm{a}-\mathrm{Fe}_{2} \mathrm{O}_{3}$ were also measured for comparison. As shown in Fig. 5-a, the photodegradation rate of MB was found to be the highest using the ternary $\mathrm{Ag} @ \mathrm{TiO}_{2} / \mathrm{a}-\mathrm{Fe}_{2} \mathrm{O}_{3}$ photocatalyst. On the other side, the photodegradation rate using pristine $\mathrm{a}-$ $\mathrm{Fe}_{2} \mathrm{O}_{3}$ photocatalyst is the lowest. However, the photocatalytic performance of hematite $\mathrm{a}-\mathrm{Fe}_{2} \mathrm{O}_{3}$ is

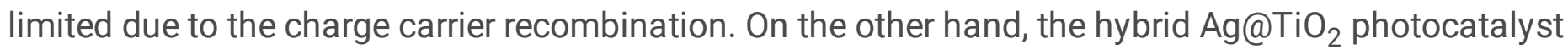
exhibited interesting photodegradation rate due to the presence of plasmonic AgNPs which can generate more electrons and therefore boost the photocatalytic activity of $\mathrm{TiO}_{2}$. It can be seen that ternary $\mathrm{Ag} @ \mathrm{TiO}_{2} / \mathrm{a}-\mathrm{Fe}_{2} \mathrm{O}_{3}$ photocatalyst exhibits much higher photodegradation activities than that of hybrid $\mathrm{Ag} @ \mathrm{TiO}_{2}$ may be due to the support given by $\mathrm{a}-\mathrm{Fe}_{2} \mathrm{O}_{3} \mathrm{NPs}$ which increases the surface are of the photocatalyst and also increases the light absorption which generates more electron-hole pairs for dye photodegradation and consequently enhances the photocatalytic activity of the ternary nanocomposite. To examine the reaction kinetics of photocatalysts, experimental data were fitted by a first-order kinetic equation $\left(\operatorname{Ln}\left(\mathrm{C}_{0} / \mathrm{C}\right)=\mathrm{k}_{\mathrm{ap}} \mathrm{t}\right)$ using the Langmuir-Hinshelwood model. It can be seen from the curves displayed in Fig. 5-b that the photodegradation process followed first order kinetics. A proposed possible photocatalytic mechanism is illustrated in Fig. 5-c. After excitation the $\mathrm{VB}$ electrons of both $\mathrm{TiO}_{2}$ and a$\mathrm{Fe}_{2} \mathrm{O}_{3}$ were excited to the $\mathrm{CB}$, creating holes in the VB. These photogenerated electrons-holes recombined rapidly, leading to a low photocatalytic performance of the photocatalyst. However, after loading the AgNPs, the photogenerated electrons could be continuously transported from $\mathrm{TiO}_{2}$ and $\mathrm{a}-\mathrm{Fe}_{2} \mathrm{O}_{3}$ to $\mathrm{AgNPs}$. Those vector transfers led to spatial separation of the photogenerated carries with an electron transferred to AgNPs while the holes remain trapped at the $\mathrm{TiO}_{2}$ and $\mathrm{a}-\mathrm{Fe}_{2} \mathrm{O}_{3}$ surface. Subsequently, the adsorbed oxygen molecule $\left(\mathrm{O}_{2}\right)$ can after that react with electrons produce therefore reactive oxygen species (such $\left.\mathrm{asO}_{2} \cdot{ }^{-}, . \mathrm{O}^{2-}\right)$ that could oxidize and destruct MB dyes. 


\section{Conclusion}

In summary, the synthesis of ternary $\mathrm{Ag} @ \mathrm{TiO}_{2} / \mathrm{a}-\mathrm{Fe}_{2} \mathrm{O}_{3}$ nanocomposite using modified solvothermal protocol was reported. Physicochemical properties of the designed photocatalyst are found by means of various modern techniques such as XRD, TEM/HRTEM, XPS and UV-visible. The designed photocatalyst exhibited the highest photocatalytic activity. The performance of the ternary nanocomposite could be attributed to the synergistic effects of co-loading a- $\mathrm{Fe}_{2} \mathrm{O}_{3}$ and $\mathrm{Au}$ cocatalyst with $\mathrm{TiO}_{2}$ which expand the separation efficiency of photogenerated electron-hole carriers and consequently boost the photodegradation rate.

\section{Declarations}

\section{Notes}

The authors declare no competing financial interest.

\section{ACKNOWLEDGMENTS}

Taif University Researchers Supporting Project number (TURSP-2020/28), Taif University, Taif, Saudi Arabia.

\section{References}

1. S. Omar Fawzi, P. Khasawneh, M. Palaniandy, H. Ahmadipour, Mohammadi, Mohammad Razak Bin Hamdan, Removal of acetaminophen using Fe2O3-TiO2 nanocomposites by photocatalysis under simulated solar irradiation: Optimization study. Journal of Environmental Chemical Engineering Volume 9(1), 104921 (February 2021)

2. K. Sahu, M. Dhonde, V.V.S. Murty, Preparation of copper/TiO2/ graphene oxide ternary nanocomposites and their structural, surface morphology, and optical properties. J. Mater. Sci.: Mater. Electron. 32, 15971-15980 (2021)

3. Y.-C. Zhang, Y. You, Sen Xin,Ya-XiaYin, J. Zhang, P. Wang, X. Zheng, F.-F. Cao, Yu-GuoGuo. Rice huskderived hierarchical silicon/nitrogen-doped carbon/carbon nanotube spheres as low-cost and highcapacity anodes for lithium-ion batteries. Nano Energy Volume 25, July 2016, Pages 120-127

4. Z. Fang, M. Xu, Q. Li, M. Qi, T. Xu, Z. Niu, N. Qu, J. Gu, J. Wang, D. Wang. Over-Reduction-Controlled Mixed-Valent Manganese Oxide with Tunable $\mathrm{Mn}^{2+} / \mathrm{Mn}^{3+}$ Ratio for High-Performance Asymmetric Supercapacitor with Enhanced Cycling Stability. Langmuir 2021, 37, 8, 2816-2825

5. Y. Ge, H.Luo,Juanru Huang, Z. Zhang. Visible-light-active TiO2 photocatalyst for efficient photodegradation of organic dyes. Optical Materials Volume 115, May 2021, 111058 [6] A. Temir, K. Sh Zhumadilov, M.V. Zdorovets, A. Kozlovskiy, A.V. Trukhanov. Study of the effect of doping CeO2 in $\mathrm{TeO} 2-\mathrm{MoO}-\mathrm{Bi} 2 \mathrm{O} 3$ ceramics on the phase composition, optical properties and shielding efficiency of gamma radiation. Optical Materials, Volume 115, 2021, 111037 
6. Y. Zhang, S.M. Zhao, Q.W. Su et al., Visible light response ZnO-C3N4 thin film photocatalyst. Rare Met. 40, 96-104 (2021)

7. X. He Wang, P.N. Liu, Porous Two-Dimensional Materials for Photocatalytic and Electrocatalytic Applications. June 2020 Matter 2(6):1377-1413

8. T. Xu, X. Liu, S. Wang et al., Ferroelectric Oxide Nanocomposites with Trimodal Pore Structure for High Photocatalytic Performance. Nano-Micro Lett 11, 37 (2019)

9. K.S. Mahesh Dhonde, -V.V.S. Dhonde, Murty, Novel sol-gel synthesis of Al/N co-doped TiO2 nanoparticles and their structural, optical and photocatalytic properties Journal of Materials Science: Materials in Electronics https://doi.org/10.1007/s10854-018-9962-7

10. G.C. Zhang, J. Zhong, M. Xu, Y. Yang, Yu Li, Z. Fang, S. Tang, D. Yuan, B. Wen, Jianmin Gu. Ternary BiV04/NiS/Au nanocomposites with efficient charge separations for enhanced visible light photocatalytic performance. Chem. Eng. J. 375, 122093 (2019)

11. O. Todorka Vladkova, D. Angelov, D. Stoyanova, L. Gospodinova, A. Gomese, Soarese, Filipe Mergulhaoe, lliana Ivanovac. Magnetron co-sputtered TiO2/SiO2/Ag nanocomposite thin coatings inhibiting bacterial adhesion and biofilm formation. Surf. Coat. Technol. 384, 125322 (2020)

12. M.Jayapriy and M.Arulmozhi. Beta vulgaris peel extract mediated synthesis of Ag/TiO2 nanocomposite: Characterization, evaluation of antibacterial and catalytic degradation of textile dyes-an electron relay effect

13. Inorganic Chemistry Communications Volume 128, June 2021, 108529

14. A. Mezni, M.M. Ibrahim, M. El-Kemary, A.A. Shaltout, N.Y. Mostafa, J. Ryl et al., Cathodically activated $\mathrm{Au} / \mathrm{TiO} 2$ nanocomposite synthesized by a new facile solvothermal method: an efficient electrocatalyst with Pt-like activity for hydrogen generation. Electrochim. Acta 290, 404-418 (2018)

15. A. Mezni, N. Ben Saber, M.M. Ibrahim, N. Hamdaoui, A. Alrooqi, A. Mlayah et al., Photocatalytic activity of hybrid gold-titania nanocomposites. Mater Chem Phys 221, 118e24 (2019)

16. A. Mezni, N. Ben Saber, A. Bukhari, M.M. Ibrahim, H. Al-Talhi, N.A. Alshehri et al.. Plasmonic hybrid platinumtitaniananocomposites as highly active photocatalysts:selfcleaning of cotton fiber, under solar light. J Mater Res Technol 9, 1447e56 (2020)

17. A. Mezni, N. Ben Saber, M.M. Ibrahim, M. El-Kemary, A. Aldalbahi, P. Feng et al., Facile synthesis of highly thermally stable TiO2 photocatalysts. J Chem 41, 5021 (2017)

18. Omar Fawzi Suleiman Khasawneh, Puganeshwary Palaniandy, Removal of organic pollutants from water by Fe203/TiO2 based photocatalytic degradation:, vol. 21 (A review Environmental Technology \& Innovation, February 2021), p. 101230

19. Y. Li, B. Yang, B. Liu, MOF assisted synthesis of $\mathrm{TiO} 2 / \mathrm{Au} / \mathrm{Fe} 2 \mathrm{O} 3$ hybrids with enhanced photocatalytic hydrogen production and simultaneous removal of toxic phenolic compounds. Journal of Molecular Liquids Volume 322, 15 January 2021, 114815

20. C.-L. Yanming Fu, Wu Dong, Y.-R. Zhou, Y.-C. Lu, Y. Huang, P. Liu, L. Guo, W.-C. Zhao, Chou, Shaohua Shen. A ternary nanostructured $\mathrm{Fe} 2 \mathrm{O} 3 / \mathrm{Au} / \mathrm{TiO} 2$ photoanode with reconstructed interfaces for 
efficient photoelectrocatalytic water splitting. Applied Catalysis B: Environmental Volume 260, 118206 (January 2020)

21. Yudong Xue and Yunting Wang. A review of the a-Fe2O3 (hematite) nanotube structure: recent advances in synthesis, characterization, and applications Nanoscale, 2020,12, 10912-10932

Figures

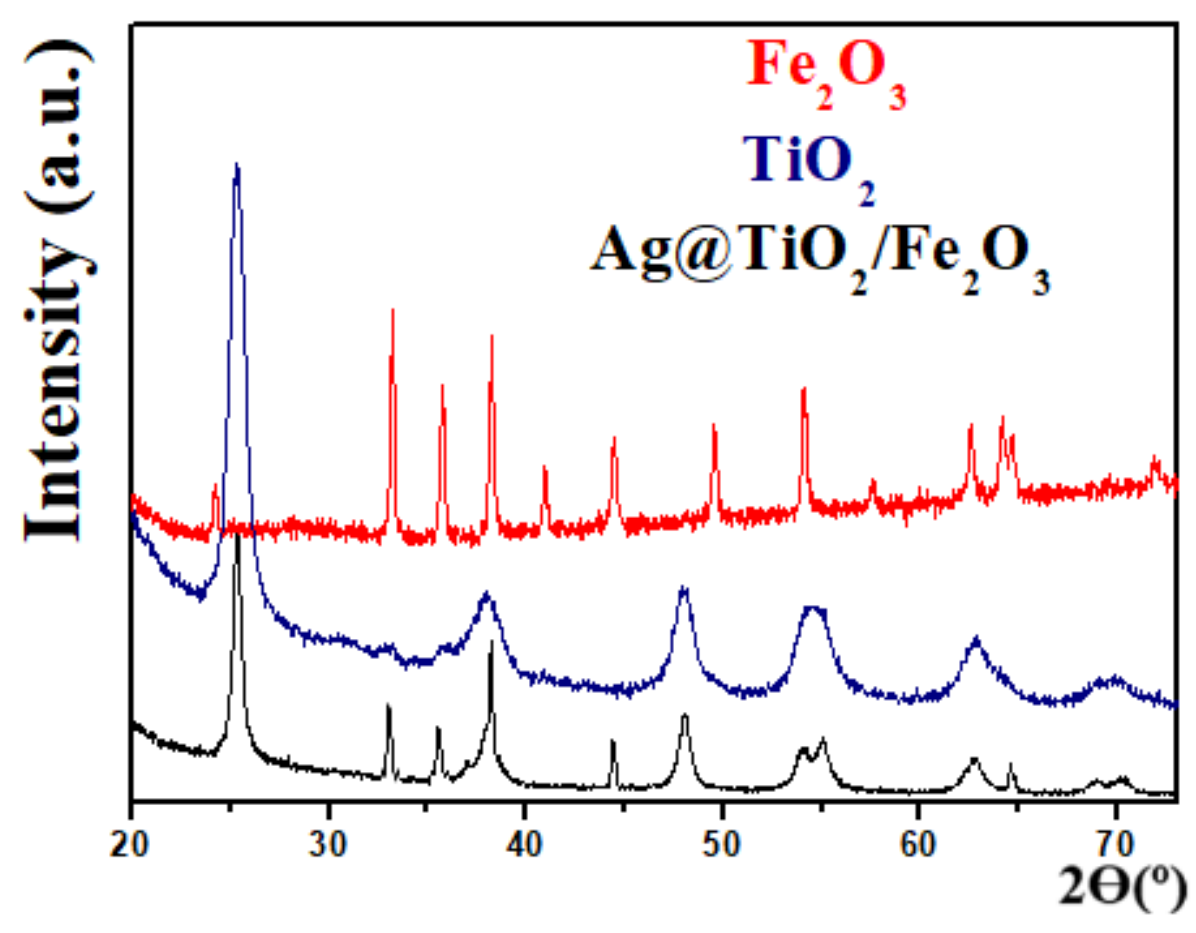

Figure 1

XRD diffractograms of bare a-Fe2O3, TiO2 and Ag@TiO2/a-Fe2O3 nanocomposite. 


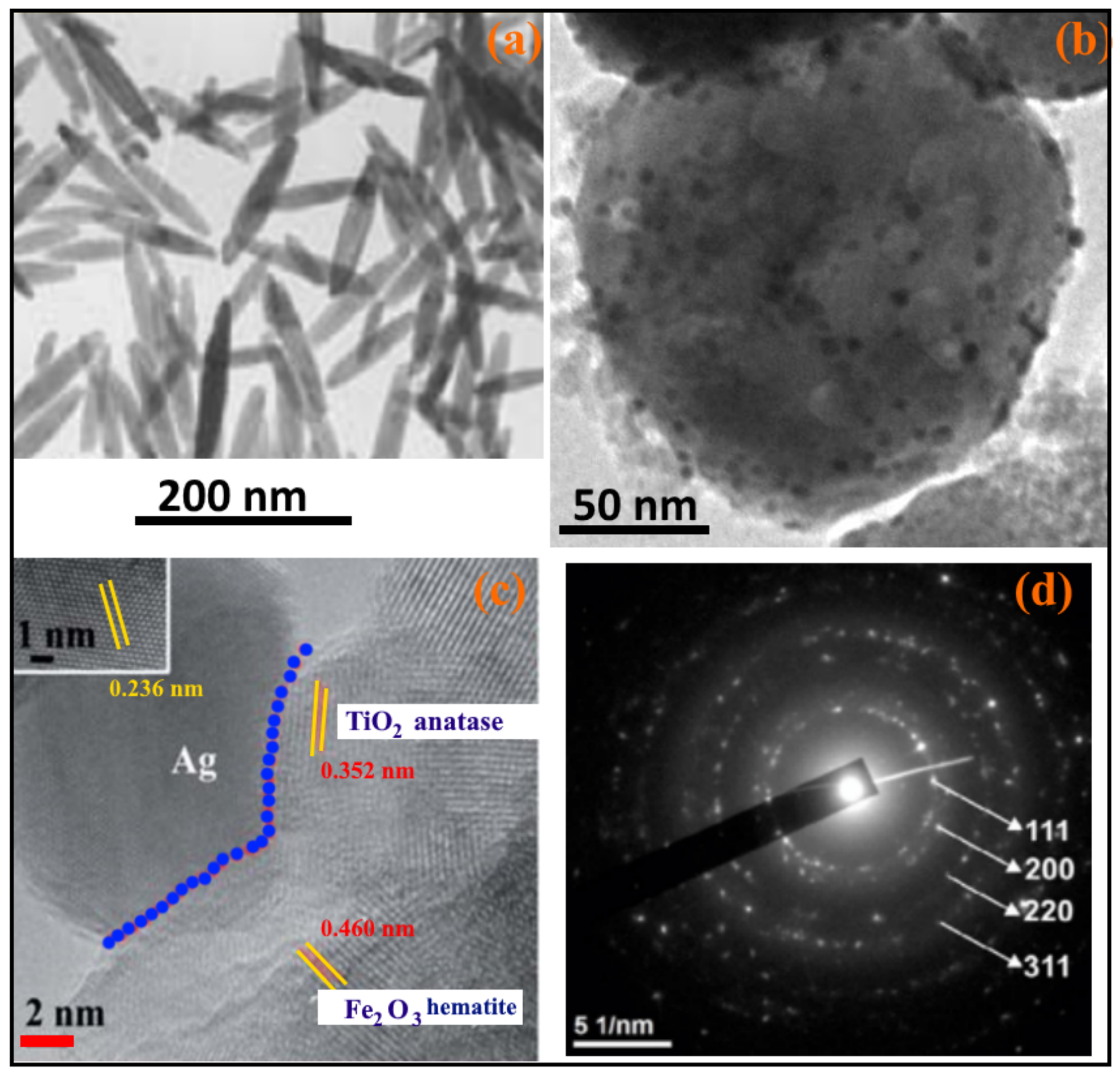

Figure 2

TEM images of (a) bare a-Fe2O3 and (b) Ag@TiO2/a-Fe2O3. (c) HRTEM image of Ag@TiO2/a-Fe2O3 with (d) SAED pattern. 


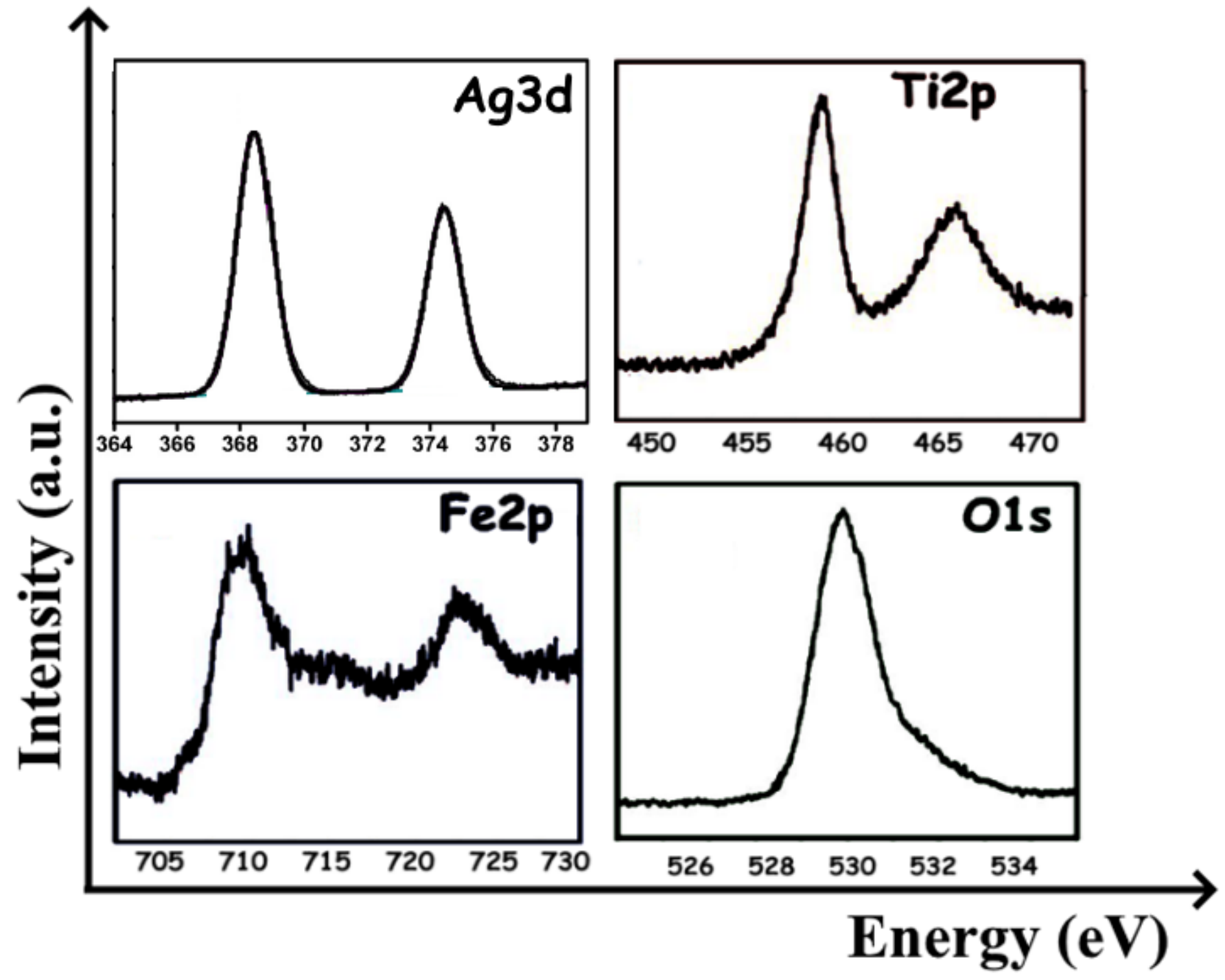

Figure 3

XPS spectra of Ag@TiO2/a-Fe2O3 

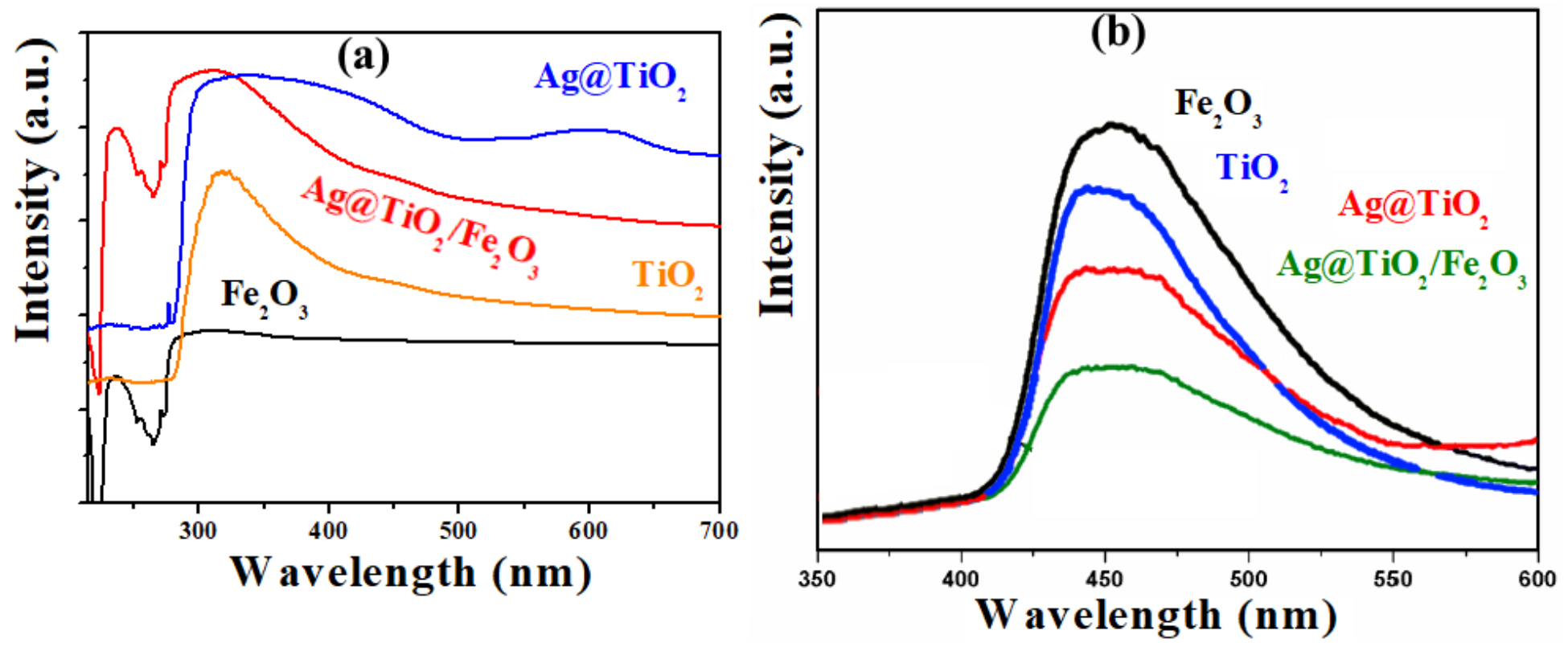

Figure 4

Optical absorption property and PL response of Ag@TiO2/a-Fe2O3 nanocomposite 

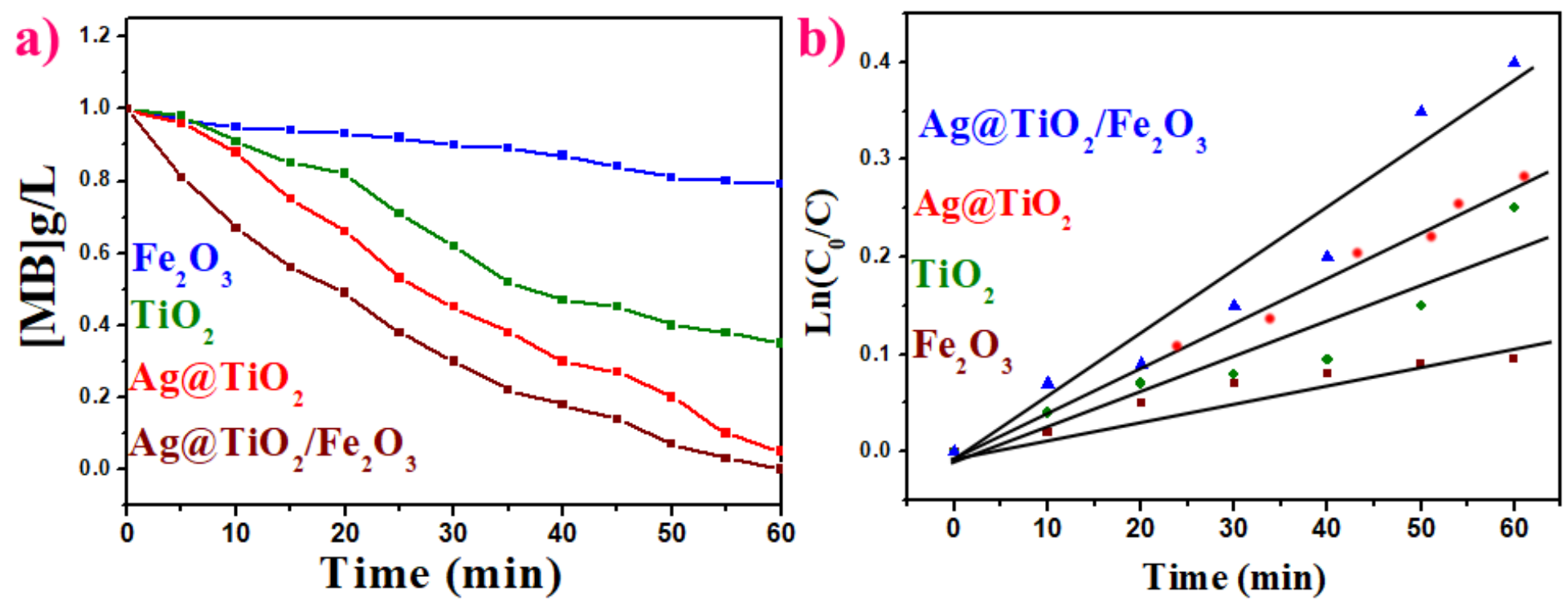

c)

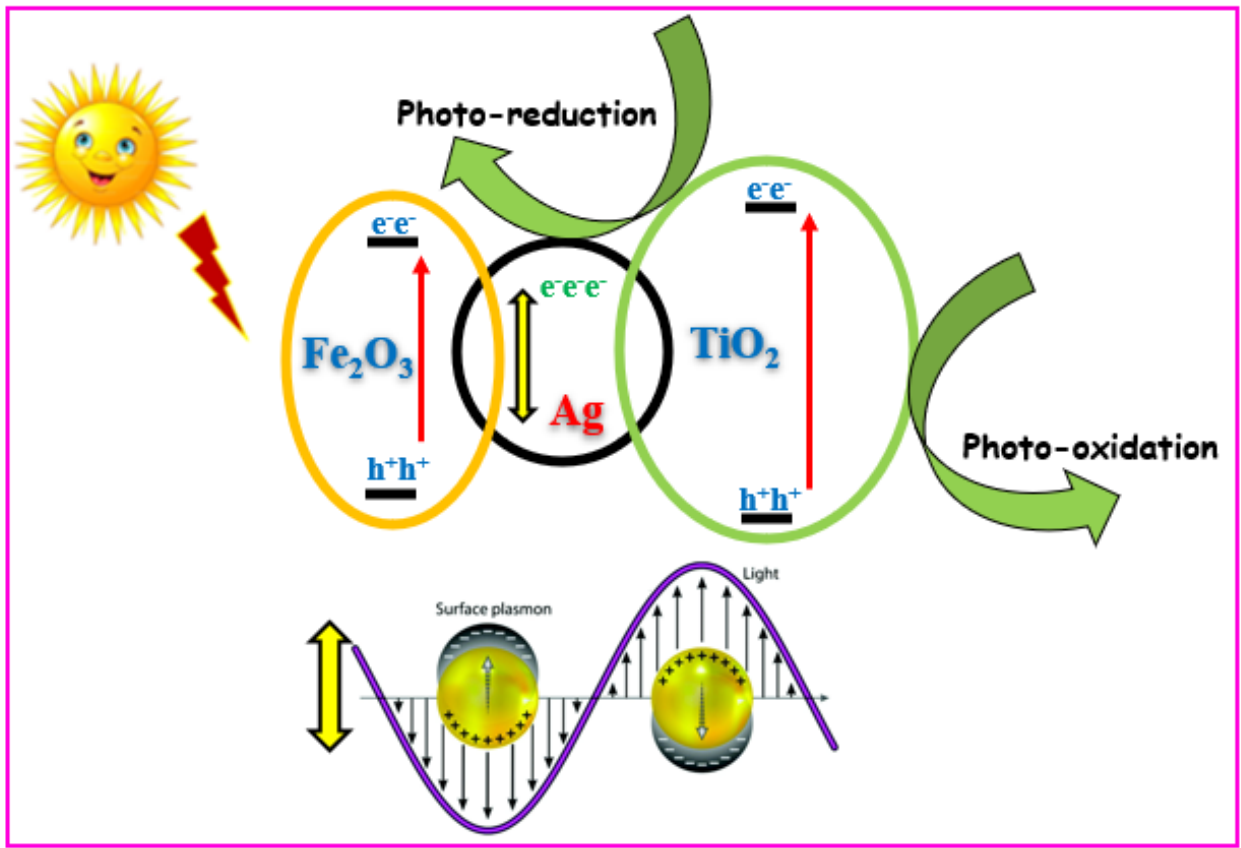

Figure 5

(a,b) Photocatalytic activity of Ag@TiO2/a-Fe2O3 Nanocomposite. (c) proposed photocatalytic mechanism

\section{Supplementary Files}

This is a list of supplementary files associated with this preprint. Click to download.

- Sl.docx 